\title{
Allergy to Insulin Analogs in Gestational Diabetes
}

\author{
Kholoud A. Ghamri, MD
}

\author{
Canadian and American Board of Internal Medicine \\ Department of Internal Medicine, Faculty of Medicine \\ King Abdulaziz University, Jeddah, Saudi Arabia
}

\section{Correspondence}

Dr. Kholoud A. Ghamri

P.O. Box 12075, Jeddah 21473, Saudi Arabia

e.M: dr_kholoudghamri@hotmail.com

Submission: 5 Mar. 2017

Accepted: 14 Mar. 2017

\section{Citation}

Ghamdi KA. Allergy to Insulin Analogs in Gestational Diabetes. JKAU Med Sci 2017; 24 (2):

41-45. DOI: 10.4197/Med. 24.2.6

\begin{abstract}
Since human recombinant insulin preparations has been introduced in medicine, allergies to insulin have rarely been reported, especially in pregnant women, who experience immune system alterations that are due to physiologic changes that occur during pregnancy. We describe a 41-year old woman who developed gestational diabetes during the second trimester and was initially treated with insulin aspart and detemir. She complained of itching, redness and a burning sensation at insulin injection sites a few weeks after administration of both insulin types. This warranted cessation of her current insulin regimen and switching to Humulin $\mathrm{R}$ and Humulin $\mathrm{N}$ due to the unavailability of insulin lispro in the hospital. In addition, patient couldn't afford buying it from outside the hospital. Her serum glucose was well controlled on this insulin regimen, and no allergic reaction was reported by the patient. Insulin allergy is an unusual finding in pregnancy, which can be managed by switching treatment regimens.
\end{abstract}

\section{Keywords}

Adverse reactions; Gestational diabetes; Insulin allergy

\section{Introduction}

$\mathrm{n}$ recent years, the prevalence of gestational diabetes mellitus (GDM) has doubled, driven mainly by changes to the recommended cutoff point for diagnosis and process of universal oral glucose tolerance testing ${ }^{[1]}$. The American Diabetes Association recommends a special diet, physical activity, and more strict glycemic control-including daily glucose monitoring and insulin injections-for the treatment of $\mathrm{GDM}^{[2]}$.

In clinical practice, cases of allergic reaction to insulin administration are uncommon and even more so in pregnant women, who have an altered immune response due to the physiologic changes that occur during pregnancy. In fact, only a few isolated cases of insulin allergy have been reported worldwide in women with $\mathrm{GDM}^{[3-5]}$. We describe the case of a 41-year-old woman who developed GDM and was referred around 24 weeks of gestation.

\section{Case Report}

The patient was a 41-year-old gravida 10 para 7 with a history of two abortions who developed GDM and was referred to our institution at around 24 weeks of gestation. Her medical history was remarkable for hypothyroidism, asthma, fatty liver disease, obstructive sleep apnea and sinusitis. Her symptoms were well controlled during pregnancy, and she was followed up at the respirology and hepatology services for bronchial asthma and fatty liver disease, respectively.

Her obstetric history was remarkable for GDM in her seventh pregnancy, which was managed using dietary measures. Her history of GDM prompted her 
physician to screen for glucose intolerance at around 16 weeks of gestation; the finding was consistent with GDM. She was admitted for blood glucose control and offered medical treatment comprising insulin aspart and detemir.

She was assessed at the obstetric medicine clinic of our institution for follow-up and was started on thyroxine, budesonide/formoterol fumarate dihydrate inhaler, salbutamol inhaler, insulin detemir and insulin aspart. She reported no history of drug allergies.

The doses of her medications were adjusted during routine follow-up visits, and her glycated hemoglobin $(\mathrm{HbA} 1 \mathrm{c})$ levels remained within a reasonable range. At presentation, $\mathrm{HbA} 1 \mathrm{c}$ was 6.1 , falling to 5.9 prior to delivery.

She had an immediate minimal burning sensation at insulin injection sites for both insulin aspart and detemir. Two weeks later (at 28 weeks gestation), her symptoms worsened and included itching, redness and a burning sensation at insulin injection sites for both types of insulin. However, it was more noticeable with insulin aspart. Physical examination revealed localized redness and small nodules in the upper thighs at injection sites.

The injection technique was reviewed by a diabetic educator, but no major concerns were raised. Therefore, we planned to switch insulin regimen to insulin lispro, but owing to the unavailability of the medication at our institution and patient was unable to provide it from outside hospital, her treatment was changed to include regular human insulin (Humulin R) and isophane (Humlin N) insulin. Blood samples were obtained for laboratory investigations, and the results are shown in Table 1.
Her serum glucose was well controlled on this insulin regimen, and she reported no allergic reaction. She was closely followed by the feto-maternal service and no concerns were raised during follow-up. However, she had to deliver via caesarean section due to fetal mal-presentation. Her postpartum oral glucose tolerance test showed impaired glucose tolerance, warranting the referral of the patient to the endocrine clinic for further follow-up.

\section{Discussion}

The National Institute for Health and Clinical Excellence advocates insulin use within a basal regimen for the management of $\mathrm{GDM}^{[6]}$. The greater evidence supports the administration of insulin detemir to control glycemic disorders in pregnancy ${ }^{[7]}$. However, there are no data that demonstrate benefits to the fetus, suggesting the lack of a strong justification to switch a pregnant woman's NPH insulin when her blood glucose is well controlled under this treatment. This was the case in our patient, who had optimal glycemic control with insulin aspart and detemir until she developed a skin reaction warranting cessation of the drugs.

Our patient had an immediate minimal burning sensation at insulin injection sites, which progressed to localized itching and redness two weeks later. The time lapse between the administration of insulin and the onset of symptoms vary between cases reported in the medical literature, with one patient reporting pruritis and tender erythematous nodules at the injection site one week $^{[5]}$ after commencement of insulin therapy and three cases reporting similar symptoms two weeks after starting treatment ${ }^{[3,5]}$. In three cases, the patients developed an urticarial reaction 8 to 24 hours after the last insulin injection ${ }^{[5]}$.

Table 1. Summary of the patient's laboratory results.

\begin{tabular}{|l|c|c|}
\hline \multicolumn{1}{|c|}{ Variable } & Results & Reference Range \\
\hline Immunoglobulin G $(\mathrm{g} / \mathrm{L})$ & 15.8 & $5.4-16.1$ \\
\hline Immunoglobulin $\mathrm{A}(\mathrm{g} / \mathrm{L})$ & 2.79 & $0.8-2.8$ \\
\hline Immunoglobulin $\mathrm{M}(\mathrm{g} / \mathrm{L})$ & 0.91 & $0.5-1.9$ \\
\hline Hemoglobin $(\mathrm{g} / \mathrm{dL})$ & 11.8 & $12-15$ \\
\hline White blood cell $(\mathrm{K} / \mu \mathrm{L})$ & 5.87 & $4.5-11.5$ \\
\hline Platelets $(\mathrm{K} / \mu \mathrm{L})$ & 280 & $150-450$ \\
\hline Automated basophils $(\mathrm{K} / \mu \mathrm{L})$ & 0.01 & $0.01-0.08$ \\
\hline Eosinophils $(\mathrm{K} / \mu \mathrm{L})$ & 0.18 & $0.04-0.40$ \\
\hline Monocytes $(\mathrm{K} / \mu \mathrm{L})$ & 0.51 & $0.04-1.00$ \\
\hline Neutrophils $(\mathrm{K} / \mu \mathrm{L})$ & 3.04 & $2.0-7.5$ \\
\hline Lymphocyte $(\mathrm{K} / \mu \mathrm{L})$ & 2.13 & $1.5-4.0$ \\
\hline
\end{tabular}


Most patients who react to insulin experience immediate Type I or immunoglobulin E-mediated allergic reaction ${ }^{[8]}$, with at least one case of death that was related to insulin. A substantial decline in the incidence of allergic episodes has, however, been reported since the development of insulin analogs ${ }^{[9]}$. Other allergic reaction types-Type III and IV-may also occur after insulin use. Further, concomitant administration of other drugs such as angiotensin converting enzyme inhibitors and 3-hydroxy-3methylglutaryl-coenzyme $A$ reductase inhibitors may trigger a local reaction to insulin ${ }^{[10]}$. The patient in our case did not receive any of these drugs.

While allergic reactions to insulin are rare, it is thought that these cases may not be due to insulin per se but to additives that are added to maintain a $\mathrm{pH}$ balance or prolong the actions of the drug in the case of intermediate and long-acting insulin preparations. Non-insulin additives that have been identified as possible culprits in suspected cases of insulin allergy include phenol, protamine sulphate, Myristic acid, mannitol, glycerol, and zinc ${ }^{[5]}$. Besides, Type I hypersensitivity reactions to latex contained in the insulin vial membrane should not be excluded. It is probable that the patient in this report may have developed an inflammatory reaction to an excipient contaminating the insulin administered. We also did not exclude the possibility of a local Type III hypersensitivity reaction. In addition, our patient did not have accompanying systemic symptoms, such as dyspnea or cough. Routine laboratory studies showed normal eosinophil count. However, this could be due to inhaled steroid effect ${ }^{[15]}$. Unfortunately, we could not measure immunoglobulin $E$ levels due to its unavailability in hospital. Neither did we send samples of the insulin detemir and insulin aspart to the manufacturer for analysis. However, clinical history and exam does suggest an allergic reaction. In addition, the history of bronchial asthma makes this patient liable to get an allergic reaction.

Physicians might face challenges in managing insulin allergies, especially in Type 1 diabetes patients. Several strategies have been proposed to manage such cases, including continuous subcutaneous infusion of short-acting insulin, offering insulin in the inhaled form, or administering other long-acting insulin preparations or antihistamine immunosuppressive treatments (in the oral and subcutaneous forms to provide symptom relief) ${ }^{[1]}$. A pancreas transplant is considered in some cases. In our case, the patient was offered insulin lispro, a rapid-acting human insulin analog. The treatment was changed to include regular human insulin (Humulin R) due to the unavailability of the drug in hospital, in addition to isophane (Humulin $\mathrm{N}$ ) insulin. She did not require antihistimane during her localized allergic reaction and her symptoms resolved after changing her insulin regimen.

In a previous study comparing insulin lispro with human insulin ${ }^{[12]}$, investigators did not find a significant reduction in neonatal hypoglycemia rates in women who received insulin lispro ( 4 out of 25 cases) compared with those who received human insulin (10 out of 46 cases). In another study that compared glargine versus $\mathrm{NPH}$ insulin ${ }^{[13]}$, the authors reported that jaundice and congenital malformations were common among pregnant women who received glargine compared with women who were NPH-treated. However, in a recent meta-analysis, NPH was reported as the basal insulin of choice in $\mathrm{GDM}^{[14]}$.

\section{Conclusion}

Insulin allergy is an unusual finding in pregnant women. Treatment cessation and switching to another insulin regimen are essential in managing these patients. Other treatment options might be necessary depending on the patient's symptoms. Optimal glycemic control can be achieved with regular human insulin (Humulin R) and isophane (NPH) insulin, which was safe in our patient.

\section{Conflict of Interest}

The author has no conflict of interest.

\section{Disclosure}

The author did not receive any type of commercial support either in forms of compensation or financial for this study. The author has no financial interest in any of the products or devices, or drugs mentioned in this article.

\section{Ethical Approval}

Obtained.

\section{References}

[1] Nankervis A, Conn J. Gestational diabetes mellitus negotiating the confusion. Aust Fam Physician 2013; 42(8): 528-531. 


\section{Allergy to Insulin Analogs in Gestational Diabetes}

K.A. Ghamri

[2] American Diabetes Association. (12) Management of diabetes in pregnancy. Diabetes Care 2015; 38 Suppl: S7779.

[3] Durand-Gonzalez KN, Guillausseau N, Anciaux ML, Hentschel V, Gayno JP. Allergy to insulin in a woman with gestational diabetes mellitus: transient efficiency of continuous subcutaneous insulin lispro infusion. Diabetes Metab 2003; 29(4 Pt 1): 432-434.

[4] Kim GJ, Kim SB, Jo SI, Shin JK, Kwon HS, Jeong H, Son JW, Lee SS, Kim SR, Kim BK, Yoo SJ. Two cases of allergy to insulin in gestational diabetes. Endocrinol Metab (Seoul) 2015; 30(3): 402-407.

[5] Morton A, Laurie J. Allergic reactions to insulin detemir in women with gestational diabetes mellitus. Aust Fam Physician 2016; 45(7): 485-486.

[6] National Collaborating Centre for Women's and Children's Health. Diabetes in Pregnancy: Management of Diabetes and Its Complications from Preconception to the Postnatal Period. London: RCOG P, 2008.

[7] Lambert K, Holt RI. The use of insulin analogues in pregnancy. Diabetes Obes Metab 2013; 15(10): 888-900.

[8] Ghazavi MK, Johnston GA. Insulin allergy. Clin Dermatol 2011; 29 (3): 300-305.

[9] Kaya A, Gungor K, Karakose S. Severe anaphylactic reaction to human insulin in a diabetic patient. J Diabetes Complications 2007; 21(2): 124-27.

[10] Pitrola D, Maclver C, Mallipedhi A, Udiawar M, Price DE, Stephens JW. Cutaneous allergy to insulin: Could statins and ACE inhibitors play a role? A case report. Diabetes Res Clin Pract 2014; 104(1): e20-22.

[11] Koroscil T, Kagzi Y, Zacharias D. Failure of multiple therapies in the treatment of a type 1 diabetic patient with insulin allergy: A case report. Endocr Pract 2011; 17(1): 91-94.

[12] Cypryk K, Sobczak M, Pertyńska-Marczewska M, ZawodniakSzałapska M, Szymczak W, Wilczyński J, et al. Pregnancy complications and perinatal outcome in diabetic women treated with Humalog (insulin lispro) or regular human insulin during pregnancy. Med Sci Monit 2004; 10(2): PI29-32.

[13] Negrato CA, Rafacho A, Negrato G, Teixeira MF, Araújo CA, Vieira L, Silva CA, Date SK, Demarchi AC, Gomes MB. Glargine vs. NPH insulin therapy in pregnancies complicated by diabetes: an observational cohort study. Diabetes Res Clin Pract 2010; 89(1): 46-51.

[14] Lv S, Wang J, Xu Y. Safety of insulin analogs during pregnancy: a meta-analysis. Arch Gynecol Obstet 2015; 292(4): 749-756.

[15] Evans PM, O'Connor BJ, Fuller RW, Barnes PJ, Chung KF. Effect of inhaled corticosteroids on peripheral blood eosinophil counts and density profiles in asthma : randomized clinical trial. Allergy Clin Immunol 1993; 91(2): 643-650. 


\section{حساسيه الانسولين لمريضه بسكري الحمل}

\section{خلود علوي صلاح غمري

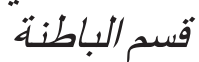 جامعه الملك عبد العزيز جده - المهلكة العربية السعودية}

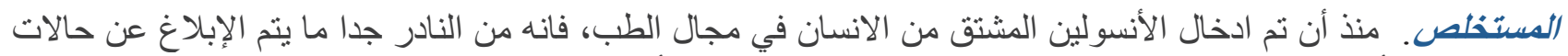

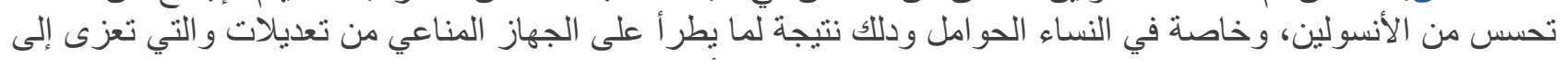

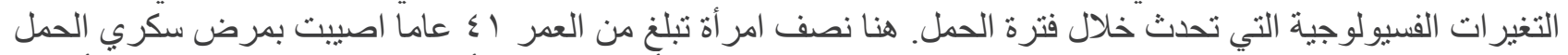

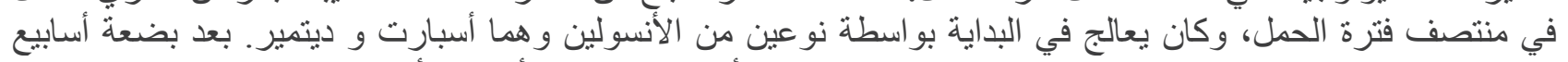

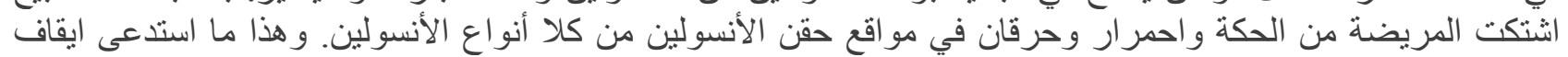

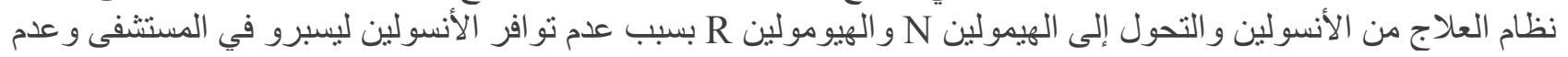

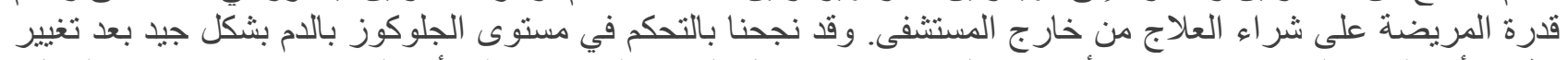

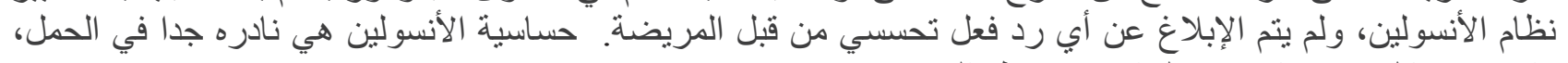
و إحدى وسائل علاجها هي تبديل او تغيير نظم العلاج. 